\title{
Developing GIOVANNI-based online prototypes to intercompare TRMM-related global gridded-precipitation products
}

\author{
Zhong Liu ${ }^{\mathrm{a}, \mathrm{b}, *}$, Dana Ostrenga ${ }^{\mathrm{a}, \mathrm{c}}$, William Teng ${ }^{\mathrm{a}, \mathrm{c}}$, Steven Kempler ${ }^{\mathrm{a}}$, Lenard Milich ${ }^{\mathrm{d}}$ \\ ${ }^{a}$ Goddard Earth Sciences Data and Information Services Center (GES DISC), NASA Goddard Space Flight Center, Code 610.2, Greenbelt, MD 20771, USA \\ ${ }^{\mathrm{b}}$ Center for Spatial Information Science and Systems (CSISS), George Mason University, USA \\ c ADNET Systems, Inc., USA \\ ${ }^{\mathrm{d}}$ Arid Lands Resource Sciences, University of Arizona, USA
}

\section{A R T I C L E I N F O}

\section{Article history:}

Received 17 May 2013

Received in revised form

8 November 2013

Accepted 26 December 2013

Available online 14 January 2014

\section{Keywords:}

Precipitation

Satellite remote sensing

Intercomparison

Uncertainty

TRMM

Online tools

\begin{abstract}
A B S T R A C T
New online prototypes have been developed to extend and enhance the previous effort by facilitating investigation of product characteristics and intercomparison of precipitation products in different algorithms as well as in different versions at different spatial scales ranging from local to global without downloading data and software. Several popular Tropical Rainfall Measuring Mission (TRMM) products and the TRMM Composite Climatology are included. In addition, users can download customized data in several popular formats for further analysis. Examples show product quality problems and differences in several monthly precipitation products. It is seen that differences in daily and monthly precipitation products are distributed unevenly in space and it is necessary to have tools such as those presented here for customized and detailed investigations. A simple time series and two area maps allow the discovery of abnormal values of 3A25 in one of the months. An example shows a V-shaped valley issue in the Version 6 3B43 time series and another example shows a sudden drop in 3A25 monthly rain rate, all of which provide important information when the products are used for long-term trend studies. Future plans include adding more products and statistical functionality in the prototypes.
\end{abstract}

(c) 2014 Elsevier Ltd. All rights reserved.

\section{Introduction}

Precipitation is an important weather variable affecting our daily lives. Each year severe droughts and floods happen around the world and often cause crop failure, heavy property damages, loss of livelihood assets, and human causalities (http://en.wikipedia.org/wiki/List_ of_natural_disasters_by_death_toll). For example, an August 1975 severe flood event in Henan Province, China, killed 230,000 people and displaced over 11 million people when No 3 Typhoon became a hovering tropical depression, and its associated heavy rain caused a dam burst (http://en.wikipedia.org/wiki/Banqiao_Dam). Accurate measurement and prediction of precipitation over both short- and longterms can greatly help hazard preparedness and mitigation efforts. However, precipitation has been notoriously difficult to measure. Across data-sparse oceans, continents, and remote regions, many in vulnerable parts of Africa, it is difficult to obtain precipitation measurement data due to the lack of rain gauges and ground radar networks, creating an obstacle for monitoring applications and forecasting verification.

\footnotetext{
* Corresponding author at: Goddard Earth Sciences Data and Information Services Center (GES DISC), NASA Goddard Space Flight Center, Code 610.2, Greenbelt, MD 20771, USA. Tel.: +1 301614 5764; fax: 13016145268.

E-mail address: Zhong.Liu@nasa.gov (Z. Liu).
}

In the past two decades, satellite-derived products have provided a cost-effective way to measure precipitation from space and fill in data gaps in data sparse regions. In recent years, algorithms that utilize multi-satellites and multi-sensors (microwave sensors and infrared sensors as well as surface raingauges) provide both researchgrade (quality-controlled) and near-real-time near-global precipitation products (e.g., Huffman et al., 2010, 1995, 2001, 2007; Joyce et al., 2004; Mahrooghy et al., 2012; Hong et al., 2007; Sorooshian et al., 2000; Behrangi et al., 2009; Aonashi et al., 2009) that are widely used in hydrometeorological research and applications. However, satellite-derived precipitation products are not perfect and issues do exist such as bias, uncertainty, sampling, sensor differences, etc. (e.g., Tian et al., 2010; Tian and Peters-Lidard, 2010; Habib et al., 2012; Yilmaz et al., 2010; Rozante et al., 2010; Chokngamwong and Chiu, 2008; Chiu et al., 2006). It is important to characterize and quantify them in order for users to apply the knowledge to their research and applications. On the other hand, as algorithms are improved and newer versions of products are released, changes in product characteristics are needed to be well understood in order for users to make adjustments or changes to their applications and research. The traditional way of acquiring this knowledge relies on journal publications; however, these usually provide a general overview and seldom address issues and changes at local or regional scales. In addition, it often takes quite a while for 
these results to be published. It can be a tedious and often time consuming, sometimes a frustrating experience if the user wants to do their own assessment from scratch, i.e., from raw data, due to various factors (data format, data volumes, data subsetting, new software development, etc.). Online tools can potentially be a solution to some of these issues, especially when the information is not available in referral articles, because downloading data and software is often not needed.

The NASA Goddard Earth Sciences Data and Information Services Center (GES DISC) is home to the NASA-JAXA (the Japan Aerospace Exploration Agency) Tropical Rainfall Measuring Mission (TRMM, Special Issue on TRMM, 2000) data archive (Liu et al., 2012). Providing such tools can facilitate precipitation data information access for the precipitation community and other communities as well. Over the years, there have been various efforts of developing online tools to analyze and visualize TRMM data (i.e., Liu et al., 2007, 2009; Liu et al. 2008; Kelley, 2013). In particular, the Climate Rainfall Data Center (CRDC) at the Colorado State University (http://rain. atmos.colostate.edu/CRDC/frame_comp.html) provides an online tool for intercomparison of TRMM and several other monthly precipitation estimates in different versions. However, the tool can only provide precipitation estimates with few plotting functions; such as time series, difference map, etc. Other precipitation related parameters (i.e., convective rain, stratiform rain) and analytical functions are not available, but also important. The prototype (Liu et al., 2009) offers more functions and data downloading, but can only allow investigation of daily products within the United States. In order to meet increasing demands for online data services from TRMM users, we are developing prototypes with new capabilities for intercomparison of near-global 3-hourly, daily and monthly gridded-precipitation products.

In this article, we describe the system in Section 2, the products in Section 3 and examples in Section 4. Summary and future plans are given in Section 5.

\section{System description}

To help users quickly gain knowledge about characteristics of precipitation products, we developed an online prototype in TOVAS (TRMM Online Visualization and Analysis System) (Liu et al., 2007, 2009) to provide a first look at data and compare daily satellite, radar and gauge precipitation products within the United States. Functions include area plot, time series, scatter plot, ASCII data output, etc. Despite its limited functionality, datasets, and spatial coverage, this tool can be used to generate customized maps and plots for comparing three daily precipitation products in the United States for the year of 2005 (Liu et al., 2009). In addition, users can download customized data in ASCII for further analysis, e.g. comparing their own data.

Because the previous prototype in TOVAS (Liu et al., 2007, 2009) is less flexible for adding new components and cannot meet increasing demands for more products, wider coverage, more functionality, and new capabilities to download data in HDF, NetCDF and KMZ (a Keyhole Markup Language file when it is compressed) for further offline analysis, new prototypes are needed.

The new prototypes are based on the GES DISC GIOVANNI (the GES-DISC Interactive Online Visualization ANd aNalysis Infrastructure) (Berrick et al., 2009; Acker and Leptoukh 2007), which is a new infrastructure that replaces the old one used in TOVAS (Liu et al., 2007, 2009). The primary goal of GIOVANNI is to provide users scientific analysis and visualization with options for refinement. The GIOVANNI's architecture (Berrick et al., 2009) consists of: (1) a detailed XML (Extendable Markup Language) schema for describing data parameters; (2) atomic (self contained) services for processing and image rendering; (3) a user-friendly interface and acceptable (few seconds $\sim$ few minutes) processing performance; and (4) a mechanism to define and capture user-based defaults (preselected options) or preferences. A GIOVANNI web client interface contains four parts (Berrick et al., 2009): (1) selection

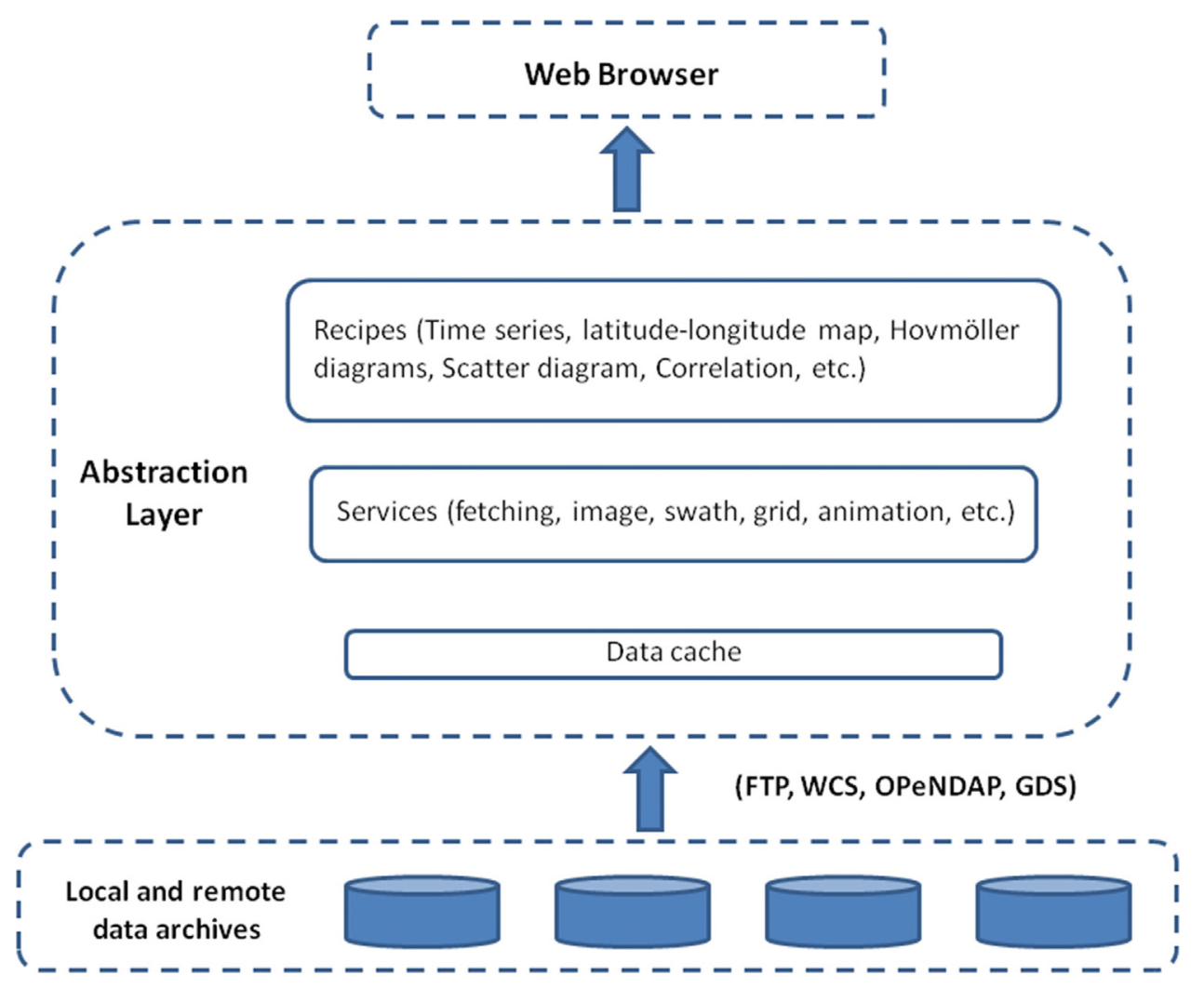

Fig. 1. Simplified GIOVANNI architecture diagram based on Berrick et al. (2009). 
page for selecting data parameters, spatial and temporal ranges, and visualization function; (2) a result page that displays visualization results and new results after refinement; (3) data lineage page that is associated with the result page including details of each processing step; and (4) a download page to allow the original and subsetted intermediate files (including the images) in various file formats (HDF, NetCDF, ASCII, KMZ). In GIOVANNI TOVAS, a simplified GIOVANNI system (Fig. 1), is used and based on Berrick et al. (2009). When a request is issued by a web user, GIOVANNI first fetches data from local or remote data archives via ftp, OPeNDAP, GDS (GrADS Data Server), etc. and caches them for services. Recipes or algorithms to compute area-averaged time series, time-averaged maps, etc., are fetched as well, based on the user's input. After these processes, the final result is delivered to the user's web browser where they can fine-tune the output, download the data for further analysis, or start over with a new analysis.

\section{Products, analytical functions and graphic user interfaces (GUIs)}

Precipitation products in the GIOVANNI TOVAS prototypes mainly consist of TRMM products along with a few products from ground observation. TRMM is a joint U.S.-Japan satellite mission to monitor tropical and subtropical $\left(40^{\circ} \mathrm{S}-40^{\circ} \mathrm{N}\right)$ precipitation and to estimate its associated latent heating (Special Issue on TRMM, 2000). TRMM provides the first detailed and comprehensive dataset on the four dimensional distribution of rainfall and latent heating over vastly under-sampled tropical and subtropical oceans and continents. TRMM was launched on November 27, 1997 and its data are archived at and distributed by the GES DISC (Liu et al., 2012). All TRMM products can be searched, ordered and downloaded via Mirador (http://mirador.gsfc.nasa.gov/). Several data services, such as format

Table 1

List of global precipitation products in GIOVANNI TOVAS for intercomparison.

\begin{tabular}{ll}
\hline $\begin{array}{l}\text { Temporal } \\
\text { resolution }\end{array}$ & Products \\
\hline 3-hourly & 3B42RT (near-real-time), 3B42 (satellite-gauge combined) \\
Daily & 3B42RT (derived), 3B42 (derived) \\
Monthly & $\begin{array}{l}\text { 3B43 (satellite-gauge combined), 3A11 (TRMM microwave } \\
\text { imager (TMI) oceanic rainfall), 3A12 (TMI), 3A25 (TRMM } \\
\text { precipitation radar (PR)), 3B31 (TMI and PR combined), }\end{array}$ \\
Climatology & $\begin{array}{l}\text { 2A12 (TMI), 2A25 (PR), 2B31 (TMI and PR combined), TCC, } \\
\text { 3B43 (satellite-gauge combined), GPCC (gauges), Willmott } \\
\text { (gauges) }\end{array}$ \\
\hline
\end{tabular}

conversion, are available in Mirador and other data services at the GES DISC (Liu et al., 2012) as well. Additional information about TRMM and its products can be obtained from the official TRMM web site (http://trmm.gsfc.nasa.gov/) and the GES DISC precipitation portal (http://disc.gsfc.nasa.gov/precipitation). Due to limited spatial and temporal data sampling in TRMM, new blended algorithms have been developed to merge microwave and infrared sensors from different satellites along with gauge data for calibration, such as the TRMM Multi-satellite Precipitation Analysis (TMPA) (Huffman et al. 1995, 1997, 2001, 2007, 2010). For near-real-time applications, the near-real-time TMPA products have been developed as well (Huffman et al., 2007, 2010).

Table 1 lists all products in the intercomparison prototypes in GIOVANNI TOVAS. They are composed of 3-hourly, daily and monthly TMPA products (archive quality and near-real-time), other monthly TRMM products, and several climatology (or map of mean values) products. Both Version 6 and Version 7 are also available for intercomparison as well. Two types of TMPA products are available, research quality (3-hourly 3B42, its daily derived from 3B42, and monthly 3B43) and near-real-time (3-hourly 3B42RT and its daily derived from 3B42RT). Additional information regarding TMPA can be found at the product web site (near-realtime: ftp://trmmopen.gsfc.nasa.gov/pub/merged/V7Documents/ 3B4XRT_doc_V7.pdf; research: ftp://meso-a.gsfc.nasa.gov/pub/ trmmdocs/3B42_3B43_doc.pdf).

One of the main goals of TRMM has been to accurately define the climatological surface rainfall in the tropics. The TRMM Composite Climatology (TCC) is a climatology of surface precipitation based on 13 years of data from TRMM (Adler et al., 2009). The TCC consists of a merger of selected TRMM rainfall products over both land and ocean to give a "TRMM-best" climatological estimate (Adler et al., 2009). There are 78 data files in this TCC product suite: 13 each (annual and month-of-year) for TRMM Version 6 data products 2A12, 2A25, 2B31, 3B43, TCC, and standard deviation of TCC. The Version 7 TCC products are being processing and will be added as soon as the processing is finished.

Functions used in GIOVANNI TOVAS are listed in Table 2 which contains the basic functions for product intercomparison, such as area plot, time series, scatter plot, animation, overlay, etc. Data formats for output data download include HDF, NetCDF, Google Earth KMZ, GIF, and ASCII, allowing users to do further customized analysis, i.e., importing the data in Microsoft Excel.

Fig. 2 is the newly designed homepage for GIOVANNI TOVAS (http://disc.sci.gsfc.nasa.gov/precipitation/tovas/). The newly added intercomparison section is found at the bottom section. For example, Fig. 3 is a screen shot of the prototype for daily precipitation product intercomparison. At the top of Fig. 3, there is a global map for area (a rectangular latitude-longitude box) selection using a computer mouse or a point selection by typing in the latitude and longitude.

Table 2

Functions supported by GIOVANNI TOVAS

\begin{tabular}{|c|c|}
\hline Function & Description \\
\hline Lat-lon map, time averaged & Lat-lon map averaged over any available data period within any rectangular area \\
\hline Lat-lon map, time averaged differences & Lat-lon map differences, averaged over any available data period within any rectangular area \\
\hline Overlay of Lat-lon maps & Overlay of Lat-lon maps averaged over any available data period within any rectangular area \\
\hline Normalized difference of Lat-lon maps & Normalized Lat-lon map differences, averaged over any available data period within any rectangular area \\
\hline Time series, area averaged & Time series averaged over any rectangular area \\
\hline Time series, area averaged differences & Time series differences averaged over any rectangular area \\
\hline Normalized difference of time series, area averaged & Normalized Time series differences averaged over any rectangular area \\
\hline Scatter plot & Two parameters in the selected time period and rectangular area \\
\hline Scatter plot, time averaged & Two parameters, averaged over any available data period within any rectangular area \\
\hline Scatter plot, area averaged & Two parameters, averaged over any rectangular area \\
\hline Correlation map & Correlation coefficient for two parameters over a specified time period and within any rectangular area \\
\hline Animation & Lat-lon maps for the selected time period and rectangular area \\
\hline
\end{tabular}


TRMM Online Visualization and Analysis System (TOVAS)

Welcome to TOVAS, a member of the Giovanni (GES-DISC Interactive Online Visualization ANd aNalysis Infrastructure) family, which provides users with an easy-to-use, Web-based interface for the visualization and analysis of global precipitation data.

Welcome to TOVAS, a member of the Giovanni (GES-DISC (Goddard Earth Sciences Data and Information Services Center) Interactive Online Visualization ANd aNalysis Infrastructure) family, which provides users with an easy-to-use, Web-based interface for the visualization and analysis of global precipitation data. See the FAQ for further usage on this tool.

Note: If you used the previous version of TOVAS, please read the following important changes:

1) The way to obtain a map for precipitation accumulated over a period has been changed in the new TOVAS. To obtain such map, select "accumulated precipitation" from the parameter list and "Lat-Lon map. Time-accumulated" from "Select Visualization."

2) The "Lat-Lon map, Time accumulated" service is intended only for this parameter, "accumulated precipitation" or the like. Using it for other parameters may not make physical sense.

3) New output formats: HDF, NetCDF, ASCIl, and Google Earth KMZ.

\section{Instances}

( ${ }^{*}$ See Below for TMPA Subset ASCII Service)

Near-Real-Time Monitoring Product (For research, use Archive Data)

Experimental Real-Time TRMM Multi-Satellite Precipitation Analysis (TMPA-RT): 3B42RT

Daily Global and Regional Rainfall (3B42RT derived)

TMPA-RT Intermediate IR Product: 3B41RT (VAR)

TMPA-RT Intermediate Microwave Product: 3B40RT ( $\mathrm{HQ}$ )

Satellite Rainfall Archives

Monthly Global Precipitation (GPCP)

3-hourly TRMM and Other Rainfall Estimate (3B42 V7)

Daily TRMM and Other Rainfall Estimate (3B42 V7 derived)

Monthly TRMM and Other Data Sources Rainfall Estimate (3B43, 3A12, 3A25 V7)

Ground Observation Archives

Monthly Willmott and Matsuura Global Precipitation (1950 - 1999)

Monthly GPCC Rainfall (2007 - Present, Monitoring Product)

Rainfall Product Intercomparison

Inter-Comparison of Rainfall Climatology (non-java version)

Beta Prototype: Inter-Comparison of TRMM L-3 V6 and V7 Monthly Products

Beta Prototype: Inter-Comparison of 3-hourly Precipitation Products

Beta Prototype: Inter-comparison of Daily Precipitation Products

Beta Prototype: Inter-comparison of Rainfall Climatology

Climatology

TRMM Composite Climatology

Fig. 2. New homepage for GIOVANNI TOVAS. The intercomparison section is located at the bottom of the page. 


\section{Daily Precipitation Inter-comparison \\ This tool allows inter-comparison of daily precipitation products.}

This tool is to inter-compare daily precipitation products. Users can generate plots for Lat-Lon Map, Time Series, Scatter Plot, and more. Animation is available only for Lat-Lon Maps. Results can be downloaded in HDF, NetCDF, ASCII, and Google Earth KMZ formats. The original data used in this tool can be downloaded from Mirador or other data services at the GES DISC. The documentation is available here. For questions, check TRMM FAQ or contact us. Acknowledgements: This tool is supported by NASA Research Opportunities in Space and Earth Science- 2010 (ROSES-2010), NNH10ZDA001N-ESDRERR, Appendix A.32: "Earth System Data Records Uncertainty Analysis" and the NASA GES DISC.

Select:

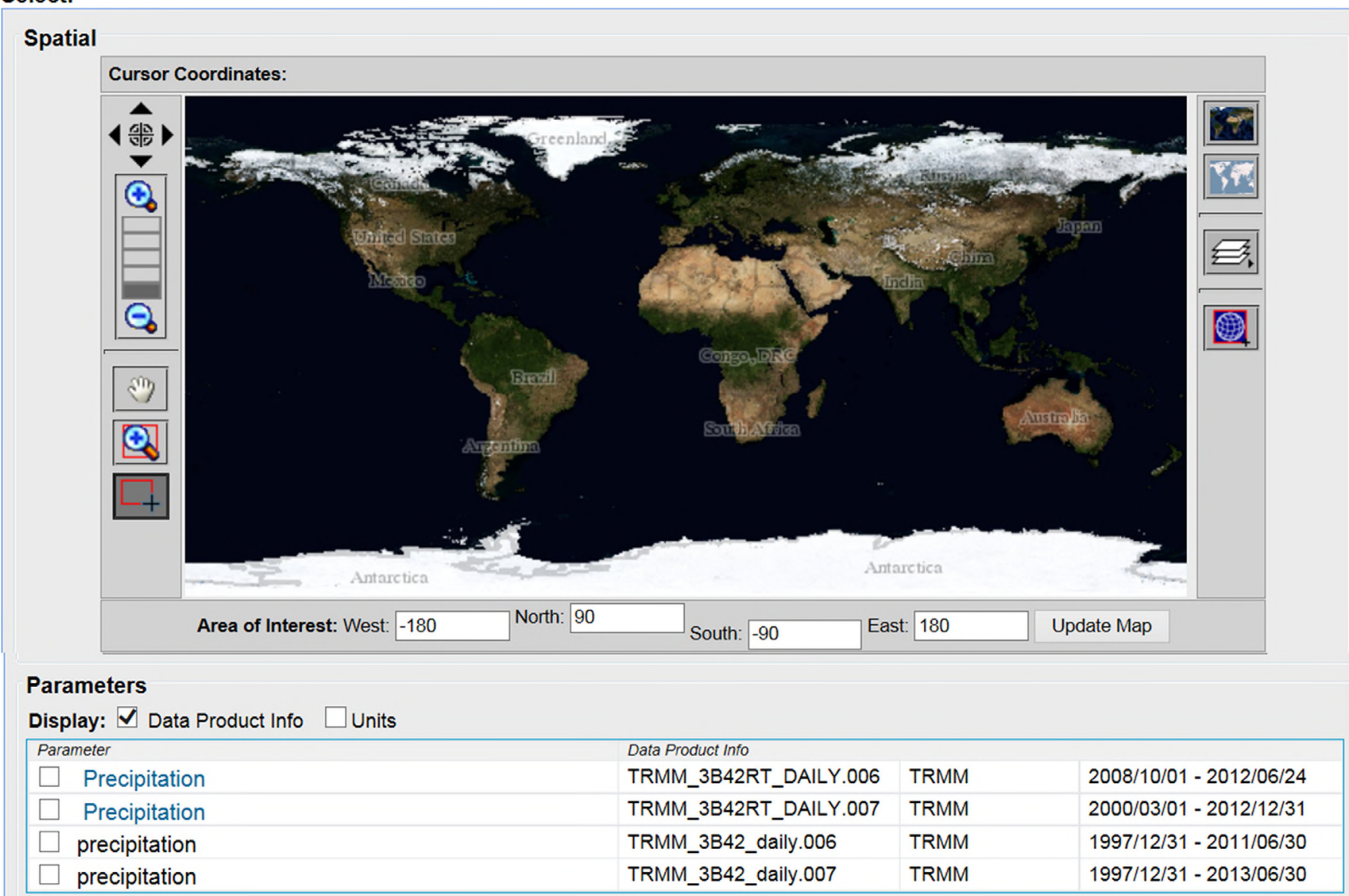

Temporal

\begin{tabular}{|c|c|c|c|c|c|}
\hline Begin Date & Year $2012 \checkmark$ & Month & $\operatorname{Dec} \vee$ & Day $31 \vee$ & (Date Begin: 31 Dec 1997) \\
\hline End Date & Year $2012 \checkmark$ & Month & Dec $\vee$ & Day $31 \vee$ & (Date End: 30 Jun 2013) \\
\hline
\end{tabular}

\section{Select Visualization:}

\begin{tabular}{|ll|l|}
\hline & \\
\hline
\end{tabular}

\section{Generate Visualization $\quad$ Reset}

Fig. 3. Screen shot of the homepage for the intercomparison of TRMM Version 6 and Version 7 TMPA 3B42 and 3B42RT daily precipitation products.

Below the map, there are different parameters in Version 6 and Version 7 daily precipitation products, time and function selection. Users can fine adjust output maps and plots by editing preferences including size, color bar, projection and smooth flag. Users can click on the "Download Data" tab to download relevant data for further analysis. GIOVANNI user manual, publications, newsletters, FAQ and user support email information can be found on the GIOVANNI website (http://disc.sci.gsfc.nasa.gov/giovanni/overview/index.html).

Fig. 4 is the GUI for TCC product intercomparison (http://disc. sci.gsfc.nasa.gov/daac-bin/tcc.pl). The pull-down menu shows all 


\section{TRMM Composite Climatology}

One of the main goals of the Tropical Rainfall Measuring Mission (TRMM) has been to accurately define the climatological surface rainfall in the tropics. This TRMM Composite Climatology (TCC) consists of a merger of selected TRMM rainfall products over both land and ocean to give a "TRMM-best" climatological estimate. There are 78 data files in this TCC product suite: 13 each (annual and month-of-year) for 2A12, 2A25, 2B31, 3B43, TCC, and standard deviation of TCC.

This tool is a prototype that allows visualization of the entire product suite with overlay of different parameters. Additional functions allow plotting scatter diagrams, time series, etc. See the FAQ for further usage on this tool. Questions and comments can be sent to gsfc-help-disc@lists.nasa.gov. The data will be ingested into the permanent archive and provided through our Mirador and other services here at the GES DISC, but can be accessed in a temporary ftp location until then at ftp://disc2.nascom.nasa.gov/data/TRMM/Gridded/TRMM_TCC.

To use the advanced application with more data products please visit: http://disc.sci.gsfc.nasa.gov/daac-bin/tcc.pl.

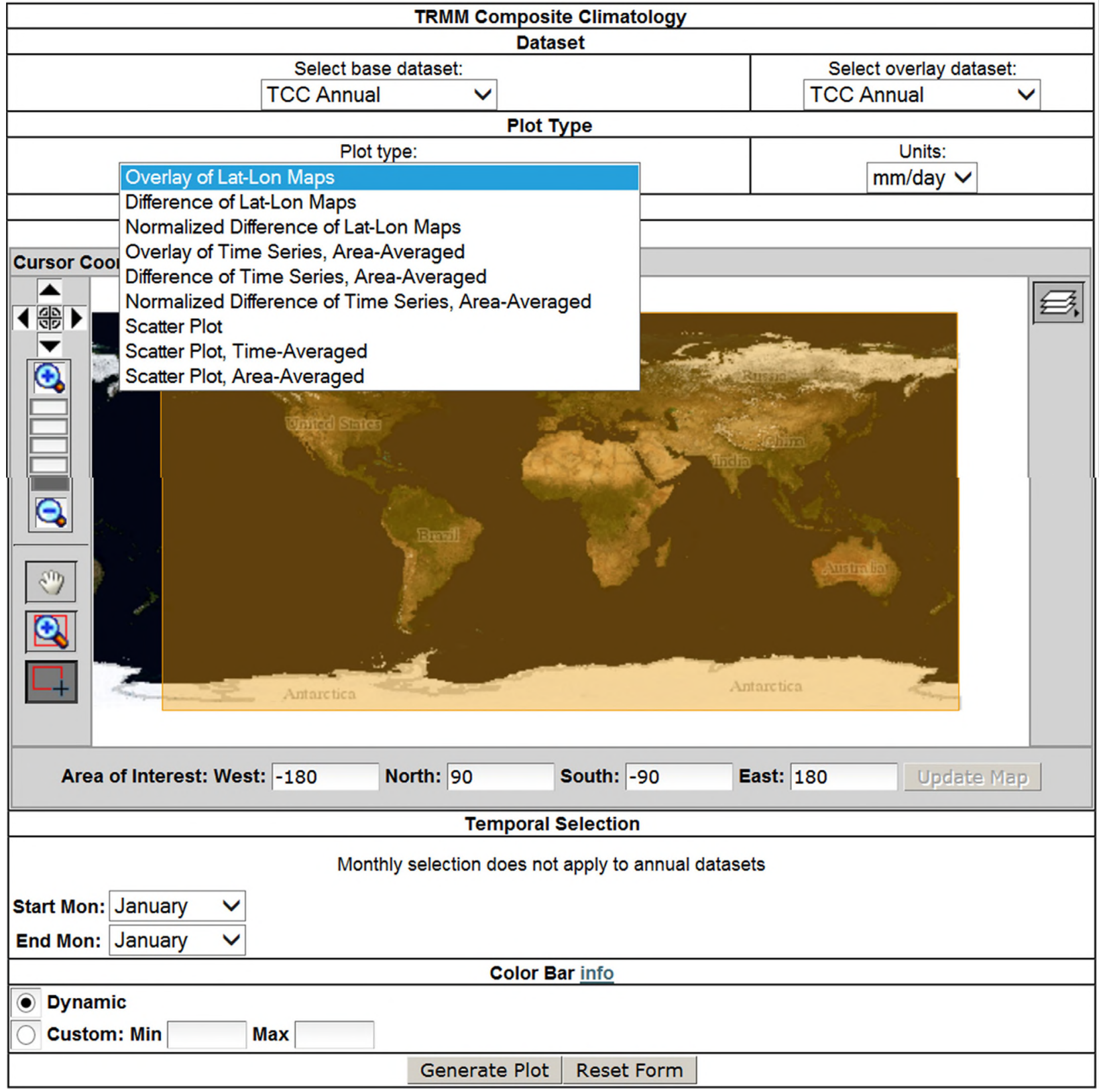

Fig. 4. Web GUI for the TRMM composite climatology (TCC) intercomparison. Functions are listed in the pull-down menu for basic intercomparison of different TRMM derived climatology products. 
the available functions. At the present, there is no data downloading capability and fine adjustment capability for visualization, but eventually, these capabilities will be added and the prototype will be migrated to the new GIOVANNI infrastructure with a similar GUI as shown in Fig. 3.

\section{Examples}

GIOVANNI TOVAS can be used to visually examine product quality. Fig. 5a shows a time series plot, generated with the monthly intercomparison prototype in Fig. 2, for the global-averaged

a

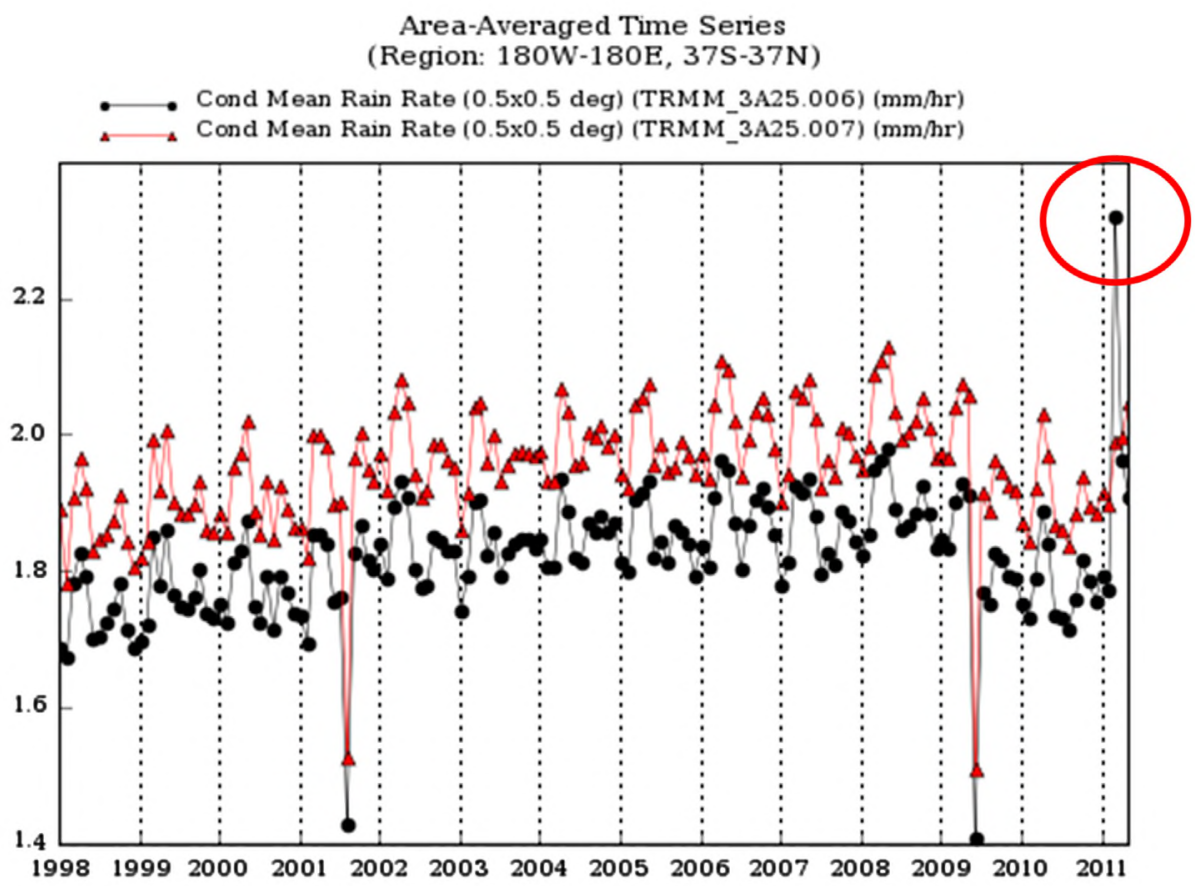

b

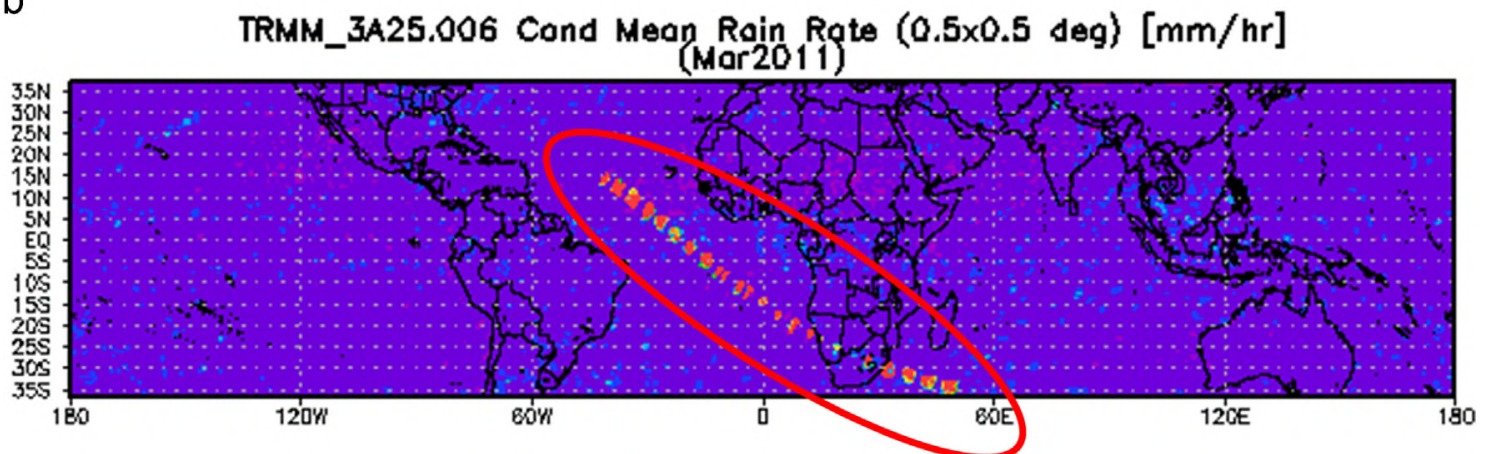

C

TRMM_3A25.007 Cond Mean Roin Rate $(0.5 \times 0.5 \mathrm{deg})[\mathrm{mm} / \mathrm{hr}]$

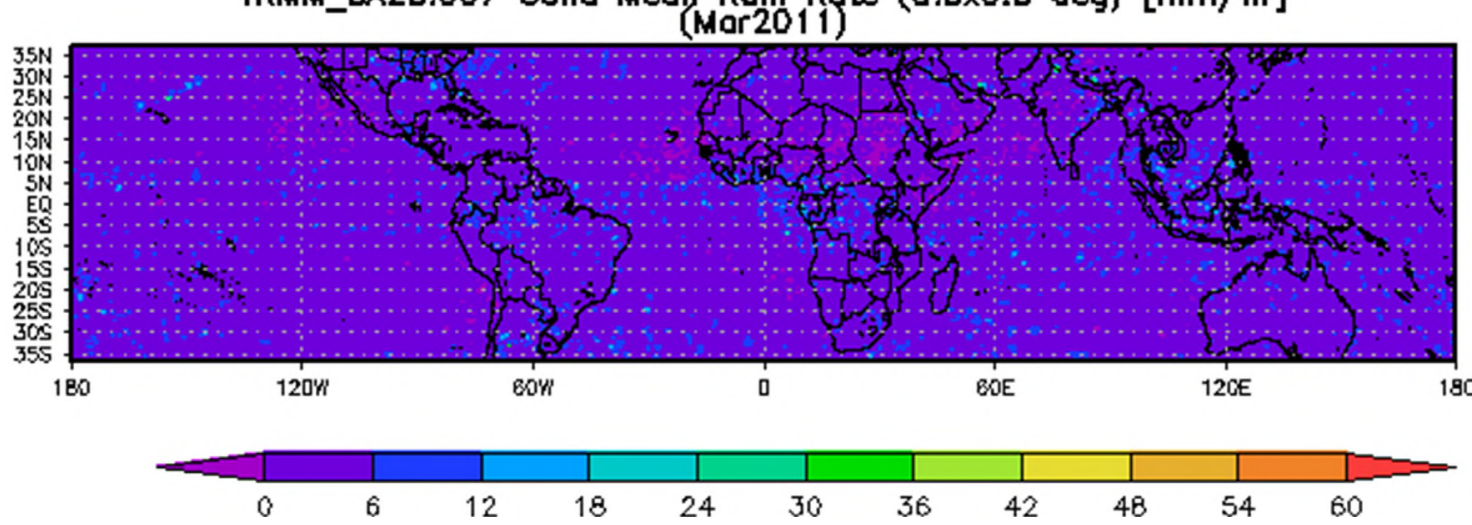

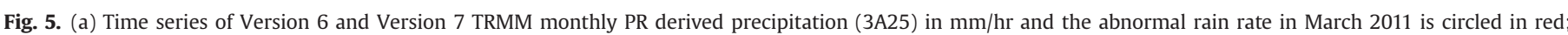

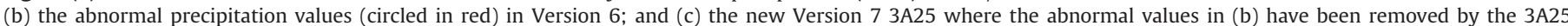
algorithm. 
Version 6 and Version 7 TRMM precipitation radar (PR) monthly rain rate estimates (3A25). In Fig. 5a, it is seen that an abnormal precipitation value (circled in red) is found in March 2011 in Version 6. Fig. 5b shows the related monthly rain rate map using the prototype. It is seen that some abnormal rain rate values (circled in red in Fig. 5b) are found by comparing those in Version 7 (Fig. 5c) where these abnormal values have been removed in Version 7 (Fig. 5c). It needs to emphasize that, for the time being, no criteria has been set in the prototype to automatically detect abnormal values and visual inspection is needed to identify abnormal values. In Fig. 5a, two low points are seen in August 2001 and June 2009, respectively. Similar maps were generated (not shown) and no similar abnormal pixels in Fig. 5b were found. By checking the Precipitation Processing System (PPS) anomalous granule table (ftp:// pps.gsfc.nasa.gov/tsdis/AB/docs/anomalous.html), it is found that there are no data available between August 7 and 242001 due to a TRMM orbit boost to extend its lifespan, and between May 29 and June 182009 due to a TRMM Precipitation Radar (PR) instrument anomaly.

One of the goals in TRMM is to develop monthly precipitation products independently from different and combined instruments in order to investigate uncertainty in precipitation products. Fig. 6a

a

\author{
Area-Averaged Time Series \\ (Region: 180W-180E, 40S-40N)
}

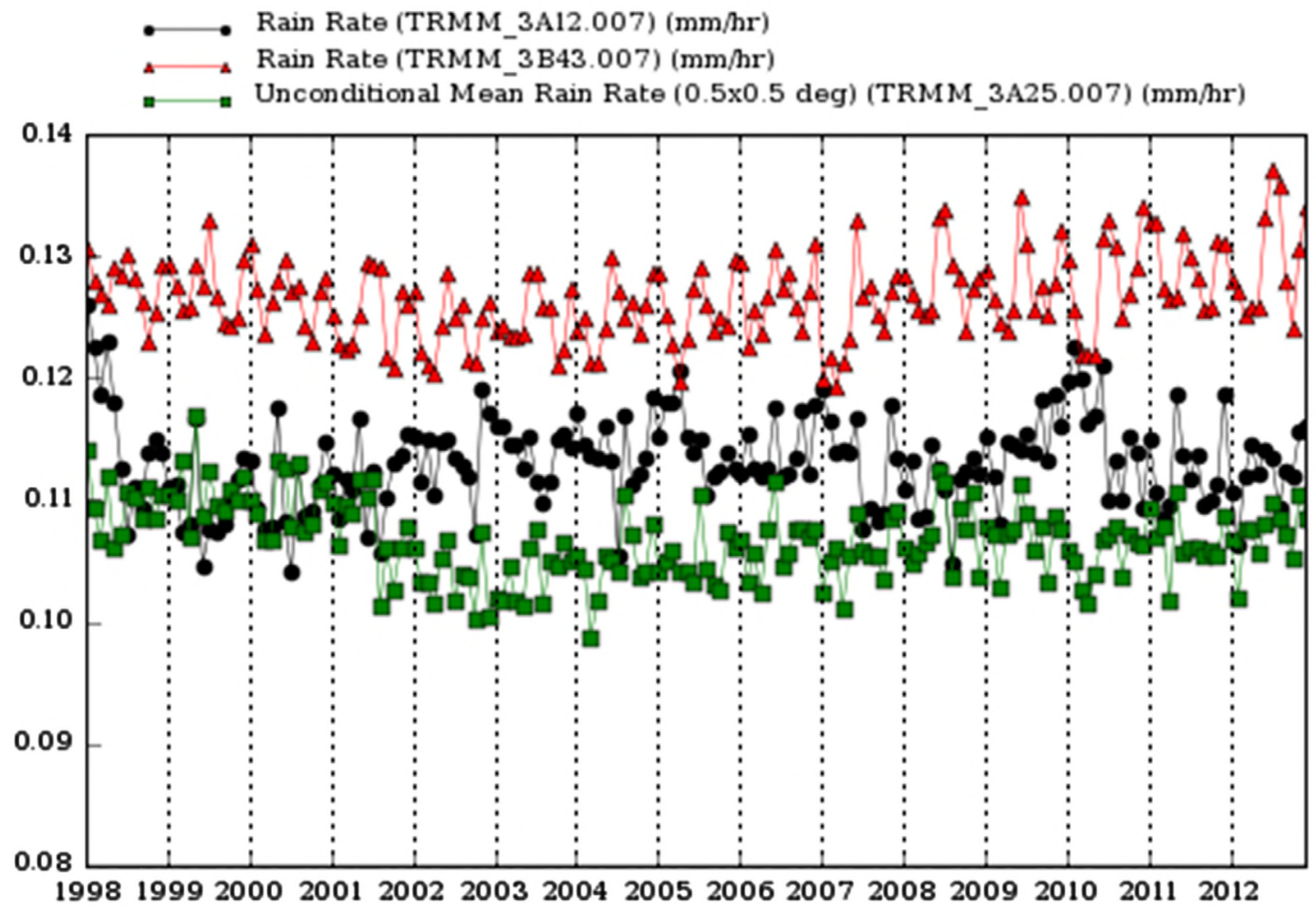

b

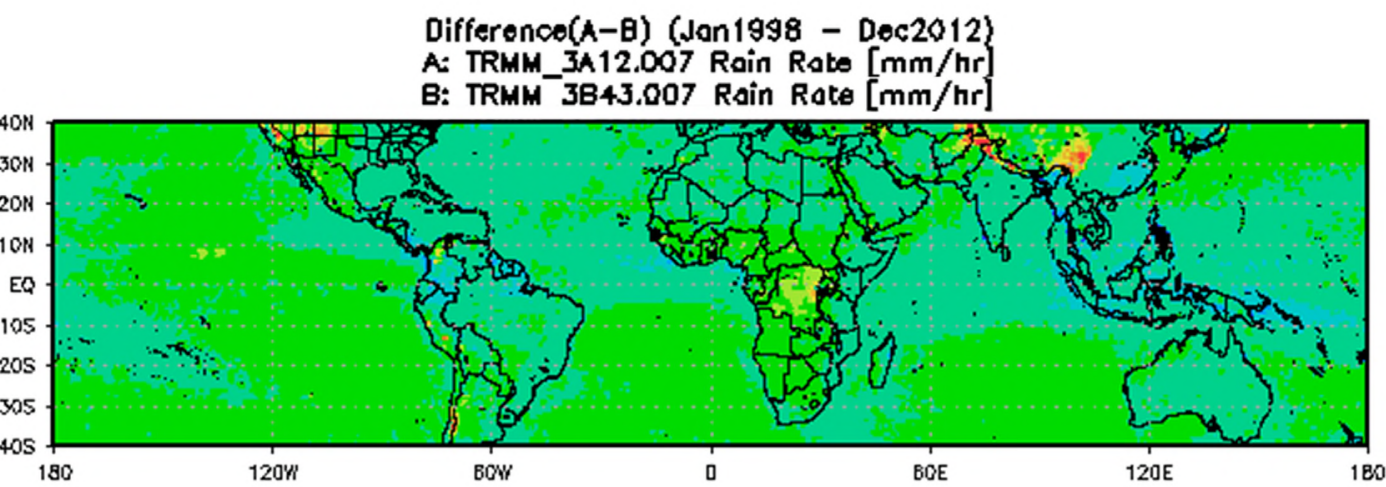

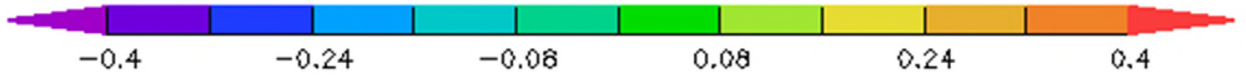

Fig. 6. (a) Time series of Version 7 TRMM 3A12, TMPA 3B43 and TRMM 3A25; and (b) difference map between Version 7 TRMM 3 A12 and TMPA 3B43. 
shows a 15-year global-averaged time series plot of TRMM 3A12, $3 \mathrm{~A} 25$ and 3B43. They are derived from the TRMM Microwave Imager (TMI), the PR, and the TMPA, respectively. It is seen that $3 \mathrm{~B} 43$ has the highest precipitation estimate, followed by $3 \mathrm{~A} 12$ and 3A25 (Fig. 6a). It is also seen that the rain rate of $3 A 25$ experienced a sudden drop after the TRMM satellite boost in August 2001, a phenomenon that has been described by Shimizu et al. (2009) and Short and Nakamura (2010). Fig. 6b is a difference map between 3A12 and 3B43, averaged over the 15-year period. The patterns of bias in Fig. $6 \mathrm{~b}$ are complicated. Higher 3A12 is found over most of the oceans south of the Equator, the North Pacific, the southern Africa, the western United States, and the Himalayas. The largest differences are found over land, in the Himalayas, the southwestern China and the northwestern United States. On the other hand, higher 3B43 is scattered around, including the northern Africa, the North Atlantic, Australia, the island countries near Indonesia, the South America, the Caribbean, the eastern China, etc.

As mentioned earlier, the TMPA products of both research quality and near-real-time have been widely used in research and applications. For example, when the Version 7 TMPA monthly product (3B43) was implemented, users can use GIOVANNI TOVAS to learn changes in product characteristics. Fig. 7a is a time series plot of the two versions of 3B43, averaged across the whole product domain $\left(50^{\circ} \mathrm{S}-50^{\circ} \mathrm{N}, 180^{\circ} \mathrm{W}-180^{\circ} \mathrm{E}\right)$. It is seen that there

a

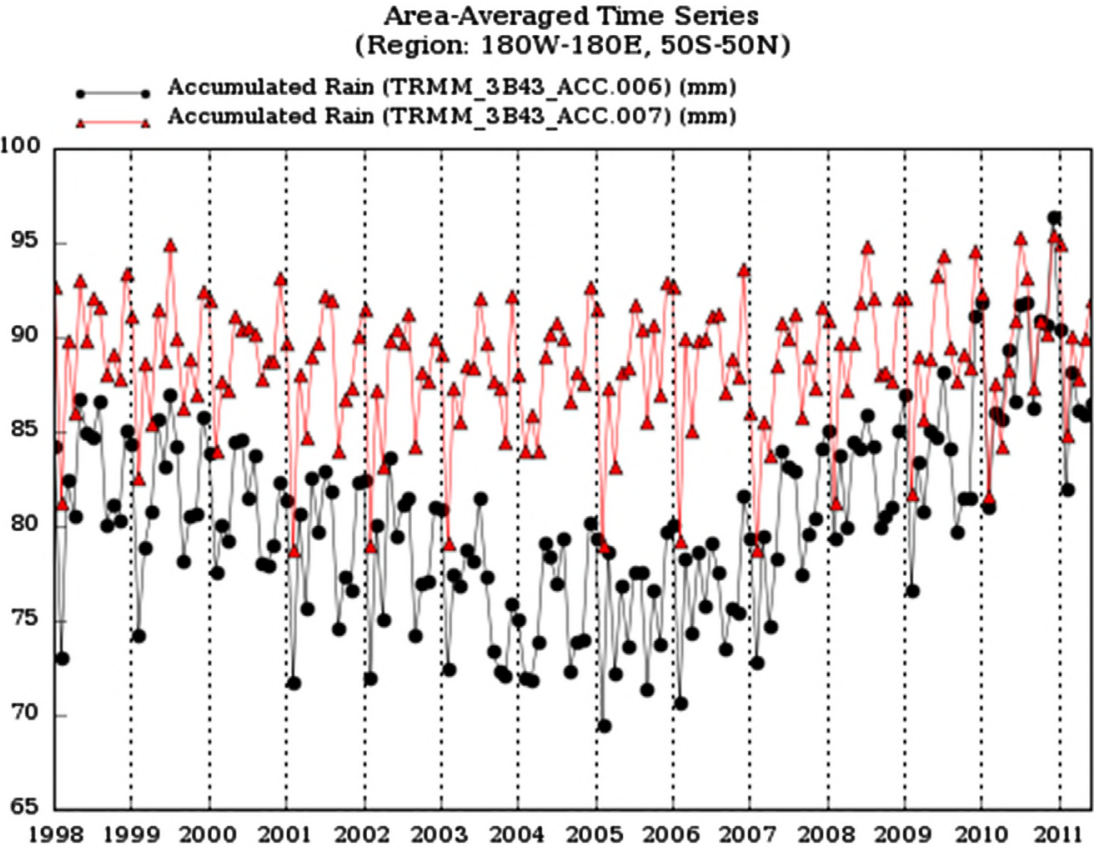

b

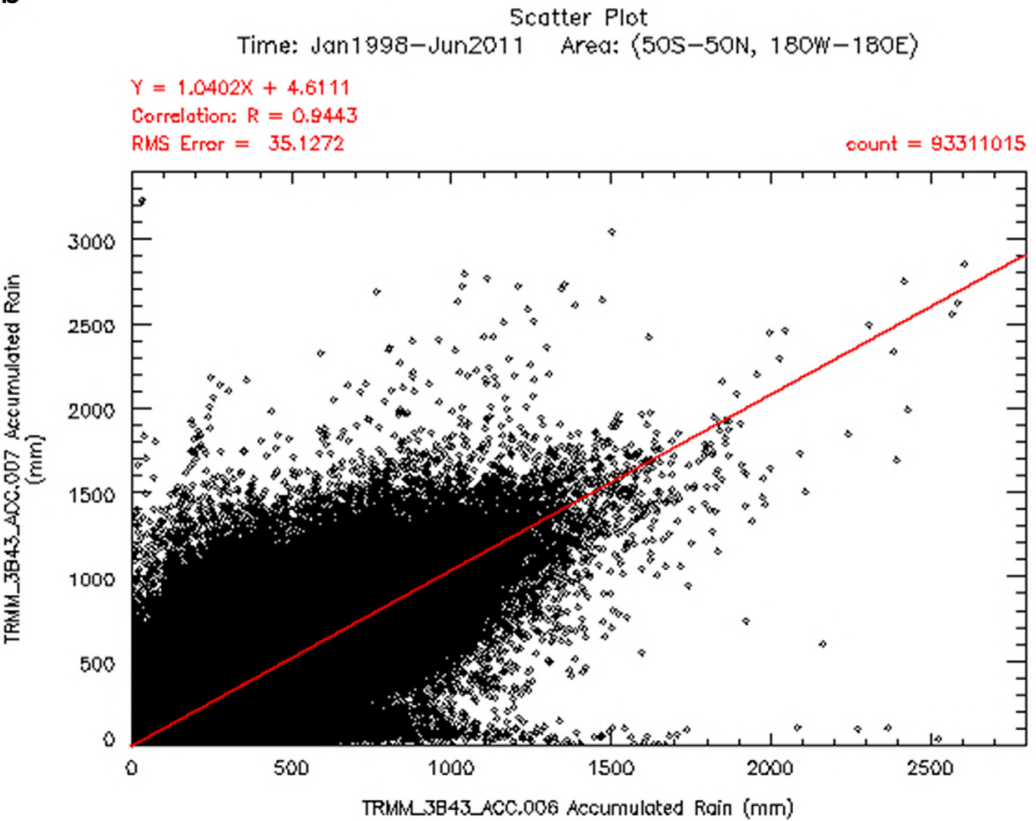

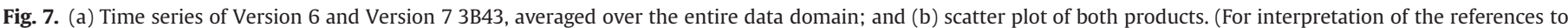
color in this figure, the reader is referred to the web version of this article.) 
a

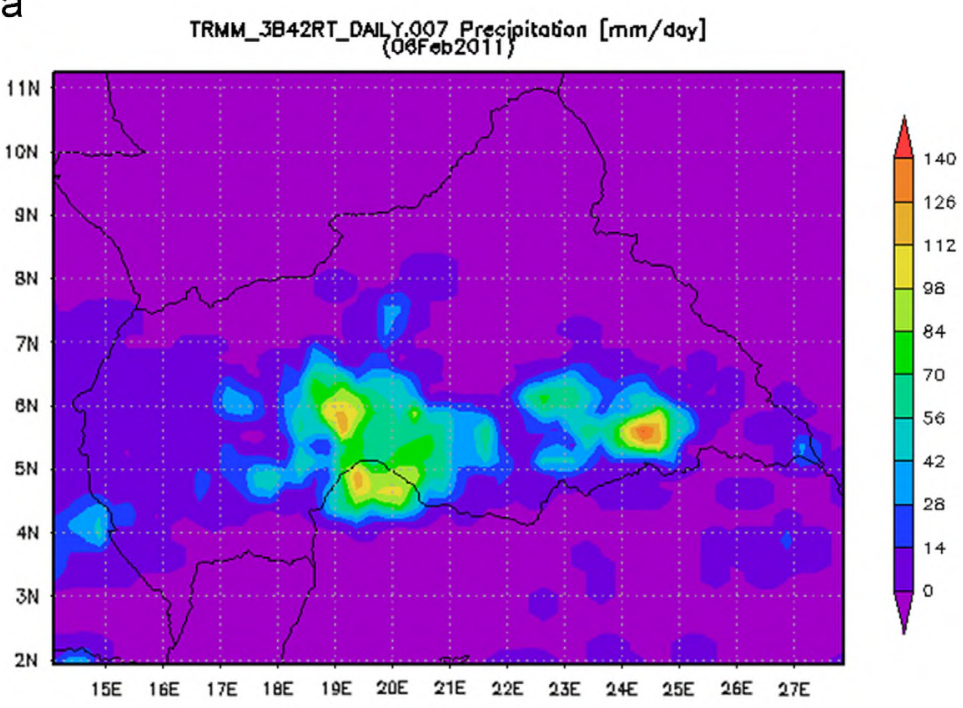

b

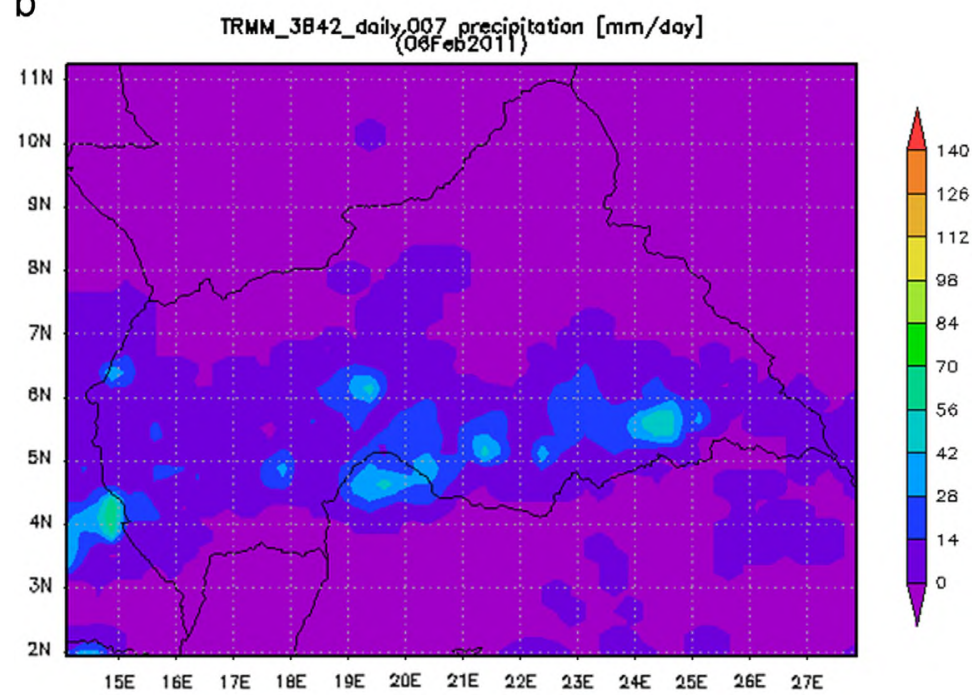

C

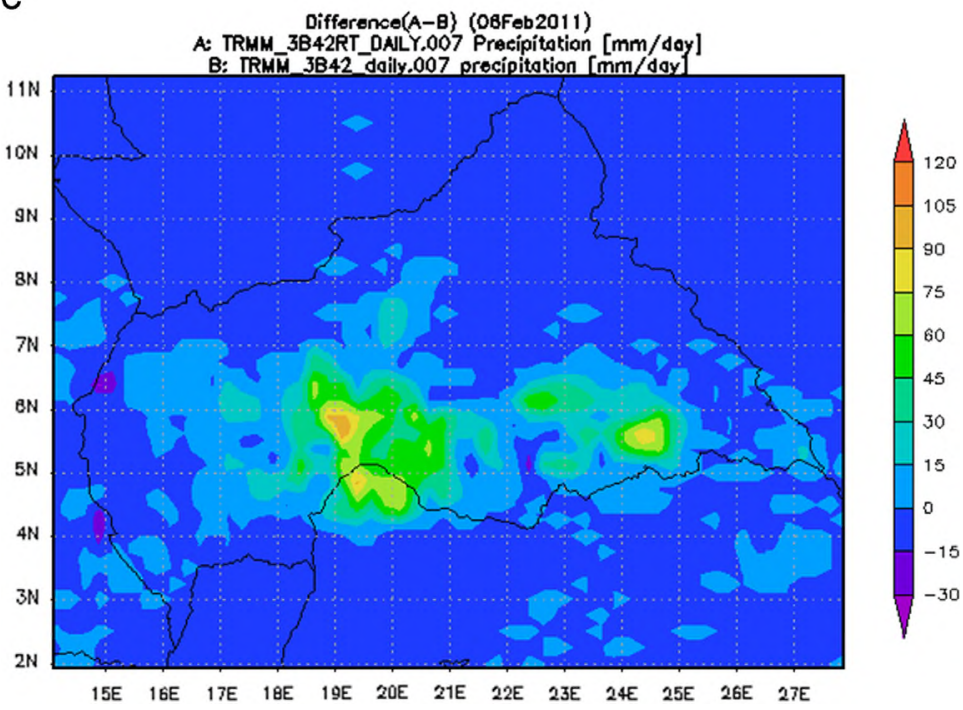

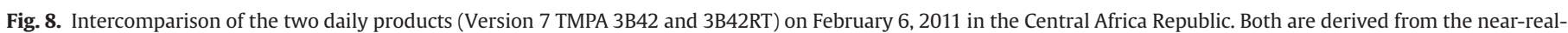
time 3-hourly TMPA 3B42RT and the research quality TMPA 3B42, separately. (a) 3B42RT daily; (b) 3B42 daily and (c) their difference map. 
is a V-shaped valley in Version 6 (black line), centered between 2004 and 2005, which has been largely corrected in Version 7 (red line). Overall, the rain rate in Version 7 is higher than that of Version 6 over the entire period from January 1998 to June 2011 (Fig. 7a). Fig. 7b is the scatter plot of the two versions' data with a fitted line and several descriptive statistics, such as root mean square difference.

Operational users, such as those who monitor flooding around the world, need to understand differences between the near-realtime product (3B42RT) and the gauge adjusted final product (3B42) in order to apply the results to their operational applications since the gauge adjusted 3B42 has a higher quality (Huffman et al., 2007, 2010). Fig. 8 contains several maps for a rain event on February 6, 2011 in the Central Africa Republic. Fig. 8a is the daily accumulated rainfall map derived from 3B42RT and Fig. 8b from 3B42. Fig. 8c is their difference map. It is seen that 3B42RT has a positive bias throughout the map, except in few spots (Fig. 8c).

Fig. 9 contains samples of TCC climatology during the summer and winter Indian monsoon seasons, using the online tool in Fig. 4. During the summer monsoon (Fig. 9a), it is seen that heavy rain

\section{a}

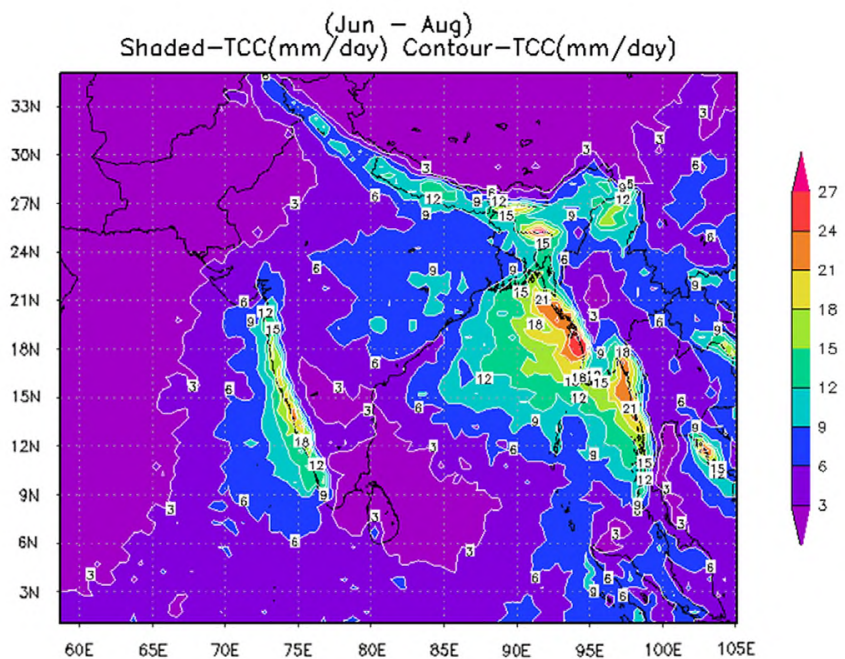

C

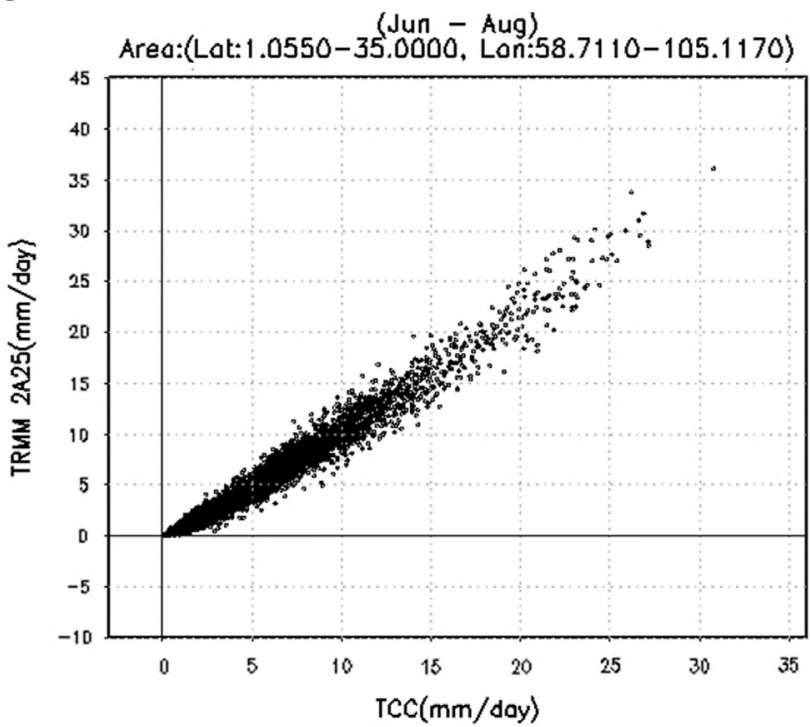

areas are located along the windward coastal oceans in western India, Burma and Thailand. During the winter monsoon (Fig. 9b), the rainy areas shift to the south, away from the continent to the south, and heavy rain areas are found near the equator. In Fig. 9c and d, the climatology derived from TRMM PR (2A25) was used to create the scatter plots for the summer (Fig. 9c) and winter (Fig. 9d) monsoon seasons. It is seen that both Fig. 9c and d show the 2A25 climatology is slightly higher against the TCC in both seasons.

In recent years, Google Earth (http://www.google.com/earth/ index.html), a popular online tool, has allowed users to explore satellite imagery with a rich collection of overlay maps, such as road, terrain, etc. In the new infrastructure of GIOVANNI TOVAS, Google Earth KMZ has been added, allowing users to explore maps generated from the intercomparison tools. Fig. 10 shows the precipitation estimates of Version 7 3B42RT (Fig. 10a), 3B42 (Fig. 10b) and their difference (Fig. 10c), averaged between $00 \mathrm{Z}$ October 24 and $00 \mathrm{Z}$ October 27, 2012. In Fig. 10a, it is seen that super storm Sandy dumped heavy rainfall in Cuba, Jamaica, Haiti, and the Dominican Republic. Estimates of heavy rainfall in both products are quite similar. The largest difference is found over the

b

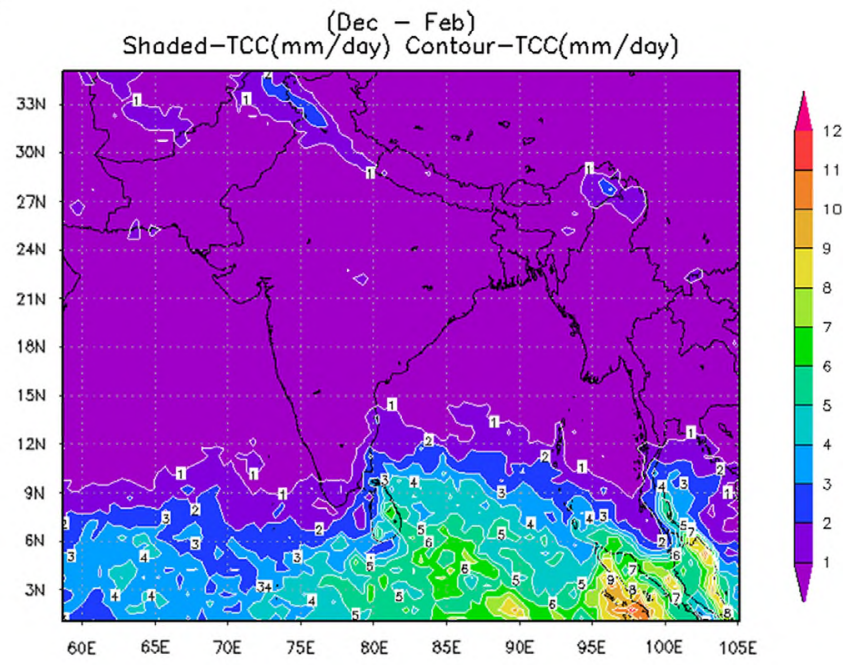

d

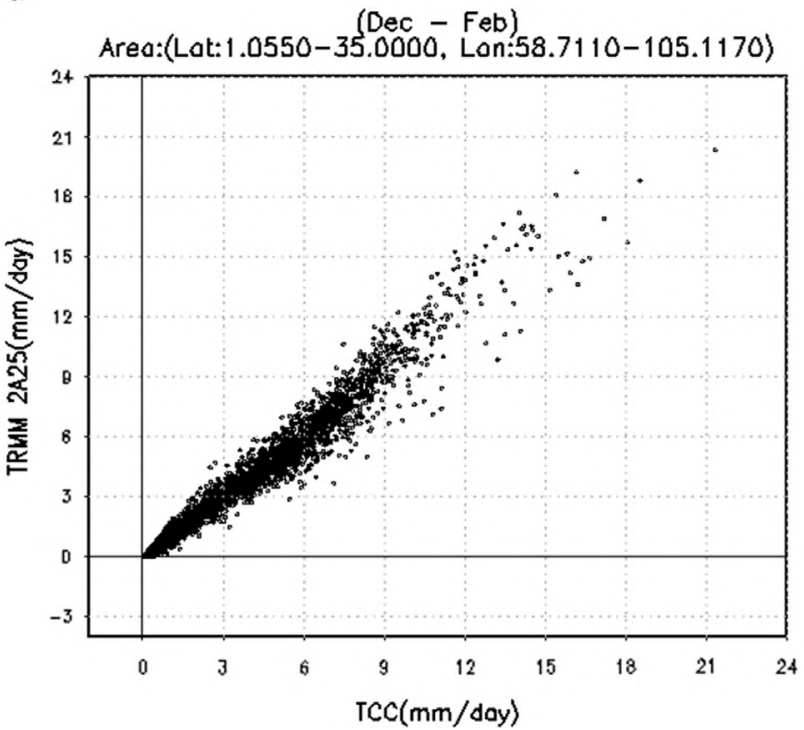

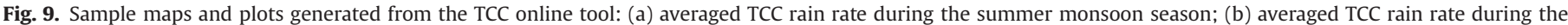
winter monsoon season; (c) scatter plot between TCC and 2A25 for the time period in (a); and (d) scatter plot between TCC and 2 A25 for the time period in (b). 
a

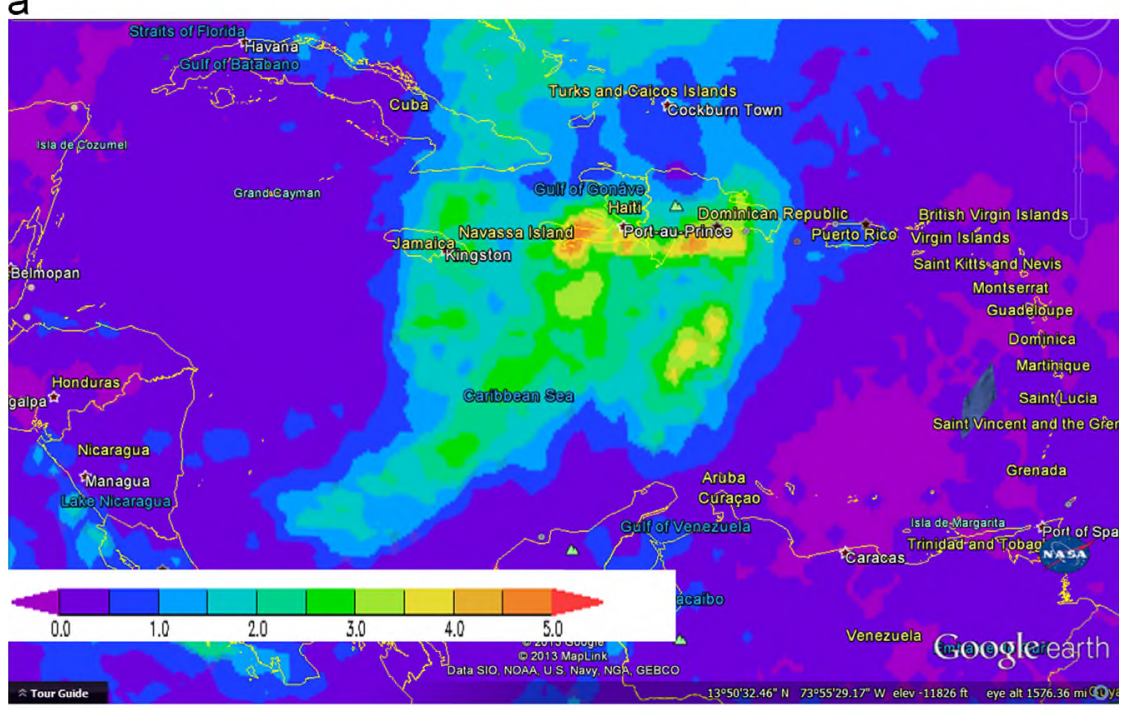

b

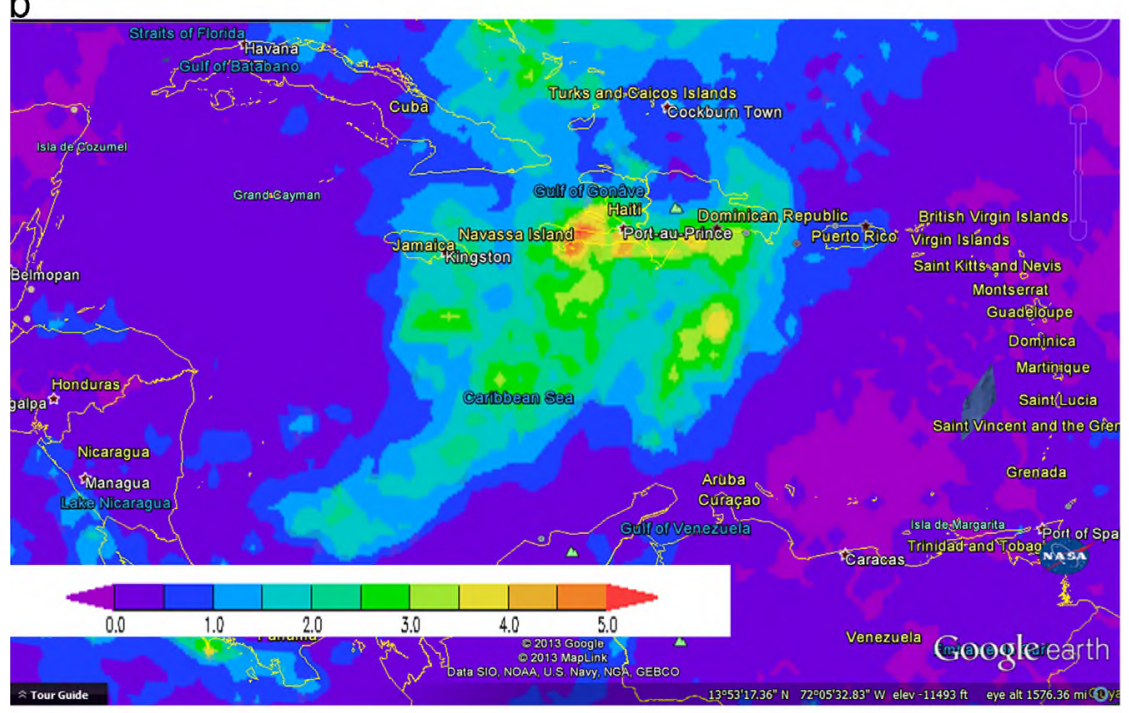

C

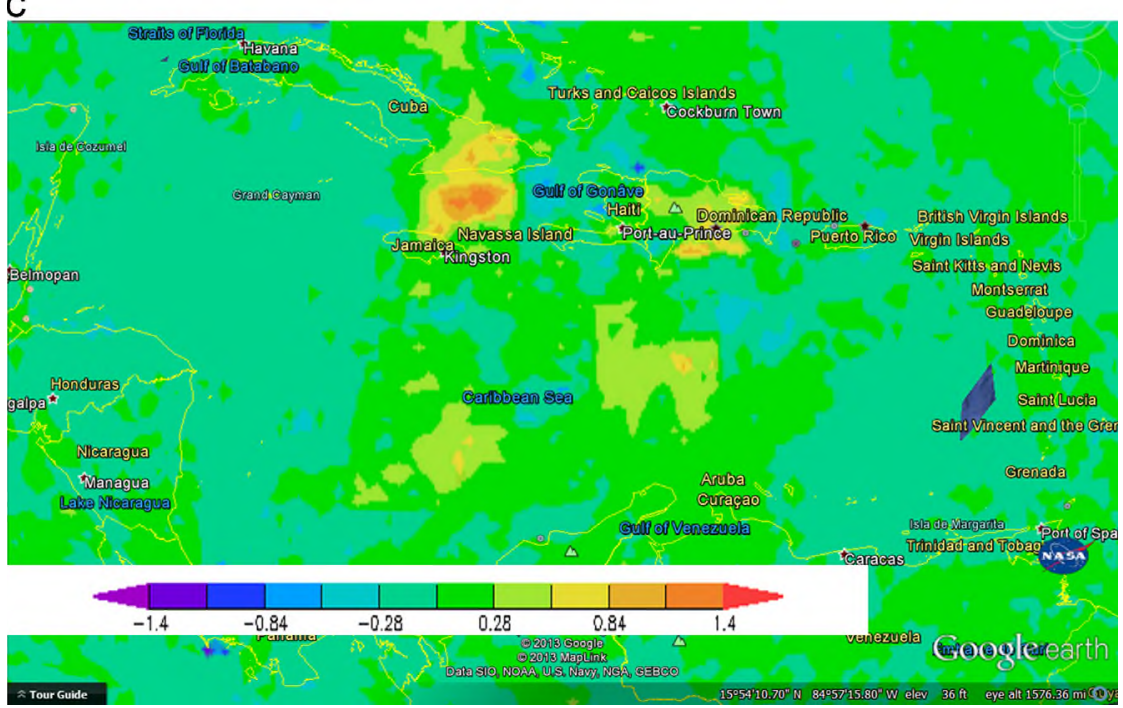

Fig. 10. Google Earth screen shots of rain rate (unit: mm/hr) averaged between 0Z October 24 and 0Z October 27, 2012: (a) 3B42RT; (b) 3B42; and (c) their difference.

ocean between Cuba and Jamaica, where the rainfall estimates of 3B42RT are larger than those of 3B42 (Fig. 10c). In short, with Google Earth, one can further explore visualization results with geographic information. Another useful data format is NetCDF which can be imported to ArcGIS (http://www.esri.com/software/ arcgis) for further analysis. 


\section{Summary and future plans}

This paper presents an ongoing new development of online prototype tools, GIOVANNI TOVAS, to assess and intercompare several satellite-based global 3-hourly, daily and monthly precipitation products and climatology products, allowing users to quickly understand product characteristics and differences in the region or at the point of interest without downloading data and software. These tools also allow intercomparing several satellite-based precipitation products in their current and previous versions to better understand changes in product characteristics due to algorithm improvement. Basic functions are available for visualization and data exploration. Several common data formats in data output are available for downloading and further offline analysis. Examples show product quality problems in several monthly precipitation products. It is seen that differences in daily and monthly precipitation products are distributed unevenly in space and it is necessary to have tools such as those presented here for customized and detailed investigations. A simple time series and two area maps allow the discovery of abnormal values of 3A25 in one of the months. An example shows a V-shaped valley issue in the Version $63 \mathrm{~B} 43$ time series and another example shows a sudden drop in 3A25 monthly rain rate, all of which provide important information when the products are used for long-term trend studies. The last example shows that differences exist in two TCC climatology products. More investigations on TCC can be done on different TCC products and on different scales with different analytical functions. The last example illustrates the use of Google Earth to explore the intercomparison results. This new capability allows users to display and explore maps generated from the intercomparison tools.

The examples show that the existing functionality and products are not enough to diagnose problems in precipitation products. More products and algorithms are still needed to help provide additional diagnostic information. For example, the TRMM orbit anomaly information should be integrated into GIOVANNI TOVAS. Additional orbital data from which monthly products derive are also helpful. Ground gauge and field campaign data are useful to identify bias between satellite-based and ground observations. There have been several online tools and databases developed by various groups. For example, the Tool for High-resolution Observation Review (THOR) that allows visualizing orbital and gridded TRMM products has been developed by the NASA Precipitation Processing System (Kelley, 2013). A TRMMbased cloud and precipitation database (Liu et al., 2008) is also useful for event-based investigation. Future collaboration with these groups is needed to maximize the existing resources and capabilities. Allowing users to upload their algorithms and data is a useful feature to be added because existing ones may not satisfy the needs of all; however security concern on the server side makes this task difficult. Developing client-side applications that provide easy access to precipitation data archived elsewhere can be a solution to this problem. For TMPA products, information about entry and drop-out of observing systems is important and should be included along with gauge weighting factor, random errors, sensors, land cover, terrain, etc. Integration of IPWG (International Precipitation Working Group) validation algorithms/statistics (http://cawcr.gov.au/projects/SatRainVal/validationintercomparison.html) into GIOVANNI TOVAS is also helpful for the intercomparison of 3-hourly and daily products. In addition, the next generation of GIOVANNI will contain more features, such as an interactive scatter map and users will have more ways to interact with data and conduct analysis tasks.

\section{Acknowledgments}

This project is supported by NASA Research Opportunities in Space and Earth Science-2010 (ROSES-2010), NNH10ZDA001N-ESDRERR,
Appendix A.32: "Earth System Data Records Uncertainty Analysis" and the NASA GES DISC. Special thanks to the GIOVANNI development team and Dr. Jianfu Pan for providing the details about the Giovanni infrastructure. Thanks extend to Drs. Robert Adler and Jian-Jian Wang for providing the TCC products and the description and participating in the tool development. The authors would like to thank three anonymous reviewers for their constructive comments, which have much improved the manuscript.

\section{References}

Acker, J.G., Leptoukh, G., 2007. Online analysis enhances use of NASA earth science data. Eos. Trans. Am. Geophys. Union 88 (2), 14-17.

Adler, R.F., Wang, J.-J., Gu, G., Huffman, George J., 2009. A ten-year tropical rainfall climatology based on a composite of TRMM products. J. Meteorol. Soc. Jpn. 87A, 281-293.

Aonashi, K., Awaka, J., Hirose, M., Kozu, T., Kubota, T., Liu, G., Shige, S., Kida, S., Seto, S., Takahashi, N., Takayabu, Y.N., 2009. GSMaP passive, microwave precipitation retrieval algorithm: algorithm description and validation. J. Meteorol. Soc. Jpn. 87A, 119-136.

Berrick, S.W., Leptoukh, G., Farley, J.D., Rui, H., 2009. Giovanni: a web service workflow-based data visualization and analysis system. IEEE Trans. Geosci. Remote Sensing 47 (1), 106-113.

Behrangi, A., Hsu, K.-L., Imam, B., Sorooshian, S., Huffman, G.J., Kuligowski, R.J., 2009. PERSIANN-MSA: a precipitation estimation method from satellite-based multispectral analysis. J. Hydrometeorol. 10, 1414-1429 http://dx.doi.org/10. 1175/2009JHM1139.1.

Chiu, L.S.Z., Liu, J., Vongsaard, S., Morain, A., Budge, P., Neville, Bales, C., 2006. Comparison of TRMM and water district rain rates over New Mexico. Adv. Atmos. Sci. 23 (1), 1-13.

Chokngamwong, R., Chiu, L.S., 2008. Thailand daily rainfall and comparison with TRMM products. J. Hydrometeorol. 9 (2), 256-266.

Habib, E., Haile, A.T., Tian, Y., Joyce, R.J., 2012. Evaluation of the high-resolution CMORPH satellite rainfall product using dense rain gauge observations and radar-based estimates. J. Hydrometeorol. 13, 1784-1798, http://dx.doi.org 10.1175/JHM-D-12-017.1).

Hong, Y., Gochis, D., Cheng, J., Hsu, K.-L., Sorooshian, S., 2007. Evaluation of PERSIANN-CCS rainfall measurement using the NAME event rain gauge network. J. Hydrometeorol. 8, 469-482 http://dx.doi.org/10.1175/JHM574.1.

Huffman, G.J., Adler, R.F., Rudolph, B., Schneider, U., Keehn, P., 1995. Global precipitation estimates based on a technique for combining satellite-based estimates, rain gauge analysis, and NWP model precipitation information. J. Clim. 8, 1284-1295.

Huffman, G.J., Adler, R.F., Arkin, P., Chang, A., Ferraro, R., Gruber, A., Janowiak, J., McNab, A., Rudolph, B., Schneider, U., 1997. The global precipitation climatology project (GPCP) combined precipitation dataset. Bull. Am. Meteorol. Soc. 78, $5-20$.

Huffman, G.J., Adler, R.F., Bolvin, D.T., Gu, G., Nelkin, E.J., Bowman, K.P., Hong, Y., Stocker, E.F., Wolff, D.B., 2007. The TRMM multi-satellite precipitation analysis: quasi-global, multi-year, combined-sensor precipitation estimates at fine scale. J. Hydrometeorol. 8 (1), 38-55.

Huffman, G.J., Adler, R.F., Bolvin, D.T., Nelkin, E.J., 2010. The TRMM multi-satellite precipitation analysis (TAMPA). In: Hossain, F., Gebremichael, M. (Eds.), Satellite Rainfall Applications for Surface Hydrology. Springer Verlag, Springer Dordrecht Heidelberg, London, New York, ISBN: 978-90-481-2914-0, pp. 3-22 (Chapter 1).

Huffman, G.J., Adler, R.F. Morrissey, M., Bolvin, D.T., Curtis, S., Joyce, R., McGavock, B., Susskind, J., 2001. Global precipitation at one-degree daily resolution from multi-satellite observations. J. Hydrometeorol. 2 (1), 36-50.

Joyce, R.J., Janowiak, J.E., Arkin, P.A., Xie, P., 2004. CMORPH: a method that produces global precipitation estimates from passive microwave and infrared data at high spatial and temporal resolution. J. Hydrometeorol. 5, 487-503.

Kelley, O., 2013. Adapting an existing visualization application for browser-based deployment: a case study from the Tropical Rainfall Measuring Mission. Comput. Geosci. 51, 228-237.

Liu, Z., Rui, H., Teng, W., Chiu, L., Leptoukh, G., Vicente, G., 2007. Online visualization and analysis: a new avenue to use satellite data for weather, climate and interdisciplinary research and applications. Measuring Precipitation from SpaceEURAINSAT and the Future. Advances in Global Change Research 28, 549-558.

Liu, C., Zipser, E.J., Cecil, D.J., Nesbitt, S.W., Sherwood, S., 2008, A cloud and precipitation feature database from nine years of TRMM observations. J. Appl. Meteor. Clim. 47, 2712-2728.

Liu, Z., Rui, H., Teng, W.L., Chiu, L.S., Leptoukh, G.G., Kempler, S., 2009. Developing an online information system prototype for global satellite precipitation algorithm validation and intercomparison. J. Appl. Meteorol. Climatol.-IPWC Spec. Issue 48 (12), 2581-2589.

Liu, Z., Ostrenga, D., Teng, W., Kempler, S., 2012. Tropical rainfall measuring mission (TRMM) precipitation data and services for research and applications. Bull. Am. Meteorol. Soc., http://dx.doi.org/10.1175/BAMS-D-11-00152.1.

Mahrooghy, M., Anantharaj, V.G., Younan, N.H., Aanstoos, J., Hsu, K.-L., 2012. On an enhanced PERSIANN-CCS algorithm for precipitation estimation. J. Atmos. Oceanic Technol. 29, 922-932 http://dx.doi.org/10.1175/JTECH-D-11-00146.1. 
Rozante, J.R., Moreira, D.S., de Goncalves, L.G.G., Vila, D.A., 2010. Combining TRMM and surface observations of precipitation: technique and validation over South America. Weather Forecast. 25 (3), 885-894 (June 2010).

Shimizu, S., Oki, R., Tagawa, T., Iguchi, T., Hirose, M., 2009. Evaluation of the effects of the orbit boost of the TRMM satellite on PR rain estimates. J. Meteorol. Soc. Jpn. 87A, 83-92.

Short, David A., Nakamura, Kenji, 2010. Effect of TRMM orbit boost on radar reflectivity distributions. J. Atmos. Oceanic Technol. 27, 1247-1254 http://dx doi.org/10.1175/2010JTECHA1426.1.

Sorooshian, S., Hsu, K.-L., Gao, X., Gupta, H.V., Imam, B., Braithwaite, D., 2000 Evaluation of PERSIANN system satellite-based estimates of tropical rainfall. Bull. Am. Meteorol. Soc. 81, 2035-2046 http://dx.doi.org/10.1175/1520-0477.
Special Issue on the Tropical Rainfall Measuring Mission (TRMM), combined publication of the December 2000 Journal of Climate and Part 1 of the December 2000 Journal of Applied Meteorology, American Meteorological Society, Boston, MA.

Tian, Y., Peters-Lidard, C., 2010. A global map of uncertainties in satellite-based precipitation measurements. Geophys. Res. Lett. 37 (L24407), 1-6, http://dx.doi. org/10.1029/2010GL046008.

Tian, Y., Peters-Lidard, C., John, B., 2010. Real-time bias reduction for satellite-based precipitation estimates. J. Hydrometeorol. 11, 1275-1285, http://dx.doi.org/ 10.1175/2010JHN1246.1.

Yilmaz, K., Adler, R., Tian, Y., Hong, Y., Pierce, H., 2010. Evaluation of a satellitebased global flood monitoring system. Int. J. Remote Sensing 31, 3763-3782, http://dx.doi.org/10.1080/01431161.2010.483489. 